\title{
O dispositivo literatura no livro didático: reflexão pós-pandemia
}

\author{
Luiz Renato de Souza Pinto* \\ José Vinicius da Costa Filho**
}

\section{Resumo}

O que esperar da literatura no livro didático em face das novas realidades? Este artigo desenvolve reflexões sobre o dispositivo de literatura no livro didático, considerando o novo cenário pós-pandemia. Privilegia-se o diálogo com a pesquisa de Pimentel (2018) para sustentar a reflexão proposta. A metodologia qualitativa utiliza a ferramenta descritiva e de revisão bibliográfica para situar e desenvolver o objetivo da pesquisa. Resultados apontam que as relações de poder que atravessam a busca do conhecimento podem ser diminuídas com a criação de políticas públicas na área de educação, bem como de investimentos na cadeia produtiva do livro. Além disso, sinaliza para a necessidade de se melhorar os índices de interpretação das fontes e da produção discursiva, advindas de melhorias das relações docentes/discentes em nosso país. $\mathrm{O}$ artigo agrega à agenda de pesquisa ao destacar o dispositivo literatura no livro didático como ferramenta que contribui para contornar criticamente a realidade pós-pandêmica, marcada pela pós-verdade e fake news.

Palavras-chave: Dispositivo. Literatura e política educativa. Livro didático. Ensino de literatura. Crise sanitária.

\footnotetext{
* Instituto Federal de Educação, Ciência e Tecnologia de Mato Grosso (IFMT), Doutor em Literaturas de Língua Portuguesa pela Universidade Estadual Paulista "Júlio de Mesquita Filho" (UNESP), Professor do Programa de Mestrado Profissional em Educação Profissional e Tecnológica em rede (ProfEPT), Orcid: 0000-0002-4123-823X.

** Instituto Federal de Educação, Ciência e Tecnologia de Mato Grosso (IFMT), Doutor em Ciência Política pela Universidade Federal de Pernambuco (UFPE), Professor do Programa de Mestrado Profissional em Educação Profissional e Tecnológica em rede (ProfEPT), Orcid: 0000-0003-2210-3329.
} 


\title{
The literature device in textbook: post- pandemic reflection
}

\begin{abstract}
What to expect of a literature textbook in relation to the new reality? This paper establishes reflections about the literature device in the textbook considering the new post-pandemic scenery. The dialogue with Pimentel's (2018) research is favored to sustain the proposed reflection. The qualitative methodology uses the descriptive tool and bibliographic review to situated and to develop the research's aim. Results show that the power relations that cross the search for knowledge can be diminished with the creation of public politics in the area of education, as well as investments in the productive chain of books. Besides that, it signals to the need of improving the indexes of source interpretation and discursive production that has occurred from the improvement in the relation teacher/ student in our country. The paper adds to the research agenda when highlights the literature device in the textbook as a tool that contributes to contour critically the post-pandemic reality, marked with the post-truth and fake news.
\end{abstract}

Keywords: Device. Literature and educational politics. Textbook. Teaching literature. Sanitary crisis.

Recebido em: 26/07/2020 // Aceito em: 28/04/2021. 


\section{Introdução}

O humanismo moderno se engana, assim, ao estabelecer a separação entre saber e poder. Eles estão integrados, e não se trata de sonhar com um momento em que o saber não dependeria mais do poder, o que seria uma maneira de reproduzir, sob forma utópica, o mesmo humanismo. (FOUCAULT, 1998, p. 142).

O Ministério da Educação atualiza regularmente a produção dos livros didáticos a serem distribuídos em todo o território nacional. A Fundação Nacional de Desenvolvimento da Educação (FNDE), órgão do ministério que movimenta cifras astronômicas, é cargo político, ocupado por alguém da extrema confiança do ministro. Diante disso, fica a pergunta: o que esperar da literatura contida no livro didático em face das novas realidades?

O objetivo da pesquisa consiste em desenvolver reflexões sobre o dispositivo de literatura no livro didático frente ao novo cenário pós-pandemia. A metodologia qualitativa utiliza a ferramenta descritiva e de revisão bibliográfica para situar e desenvolver o objetivo proposto.

A justificativa se pauta pela premência em debater $o$ dispositivo literatura no livro didático em um mundo que passa por rápidas mudanças impostas pela pandemia, pela pós-verdade e pelas fake news. Nesse sentido, as transformações não devem ser tratadas somente como impedimentos e desafios, mas sim como possibilidade de a literatura continuar a contornar a realidade, agregando criticidade aos fluxos de interações humanas na era digital. Em termos teóricos, privilegia-se o diálogo com Pimentel (2018), cuja pesquisa empresta conceitos estruturantes para o desenvolvimento do presente estudo. 
$\mathrm{O}$ artigo se divide em quatro seções mais esta Introdução. A seção seguinte trata da institucionalização e organização do material didático no Brasil. A segunda apresenta uma discussão da pesquisa de Pimentel (2018) concernente ao dispositivo literatura no livro didático. A terceira utiliza a abordagem do citado pesquisador para refletir acerca da nova realidade que a pandemia impõe. Por desiderato, as considerações finais.

\section{Livro didático: institucionalização e organização}

A pedagogia brasílica instituída pelos jesuítas no período do Brasil colônia é explorada por Saviani (2019), para quem, em que pese o protagonismo franciscano, este não constituiu um "sistema educacional uma vez que vinham em pequenos grupos e permaneciam pouco tempo em cada região. Com isso acabaram eclipsados". (SAVIANI, 2019, p. 40). Os inacianos acabaram por implementar de modo mais intransigente a educação colonial, como se afere da leitura do fragmento abaixo:

Em Manuel da Nóbrega pode-se perceber com clareza a articulação das ideias educacionais em seus três aspectos: a filosofia da educação, isto é, as ideias educacionais entendidas na sua máxima generalidade; a teoria da educação enquanto organização dos meios, aí incluídos os recursos materiais e os procedimentos de ensino necessários à realização do trabalho educativo; e a prática pedagógica enquanto realização efetiva do processo de ensino-aprendizagem. (SAVIANI, 2019, p. 443-444).

A materialidade a que se refere o autor diz respeito a espaço físico, não necessariamente a suporte material de estudo. Talvez a base de todo o conhecimento fossem as sagradas escrituras. 
Anchieta conseguiu melhores resultados, uma vez que aprendeu o idioma nativo para exercer a doutrinação, em poesia e teatro de cunho sacro.

De forma mais saliente, o uso do livro didático remonta ao período imperial, tem-se registro de sua utilização desde 1820 , quando foram instaladas as primeiras escolas públicas no país, ademais, nessa década, se inicia a produção de manuais editados nas gráficas brasileiras (ZACHEU; CASTRO, 2015).

A utilização sistemática do material ganha impulso com a criação, em 1838, do Colégio Pedro II, no Rio de Janeiro, momento em que a escola atendia extensivamente às classes privilegiadas e se estruturava sob forte influência europeia, tanto que parte dos livros utilizados nessa instituição era originária da França, traduzidos para o português (SILVA, 2012). Ao longo do século XIX, com uma escola centrada em uma política escravagista e de subserviência senhorial, não se observam mudanças substanciais.

Segundo Schwarcz (1999), em 1930, é criado o Ministério dos Negócios da Educação e Saúde Pública (MNESP), que organiza e centraliza decisões referentes à educação e saúde. Conforme Moura e Betta (2016), nesse mesmo período, Francisco Campos e Gustavo Capanema estabelecem uma política de estado voltada à educação pública, que contribui com a transformação do MNESP em Ministério da Educação e Cultura (MEC), no ano de 1937, institucionalizando também o Instituto Nacional do Livro (INL), por meio do DecretoLei $\mathrm{n}^{\circ}$ 93, de 21/12/1937. O art. $1^{\circ}$ desse decreto previa como competência do INL "promover as medidas necessárias para aumentar, melhorar e baratear a edição de livros no país bem como facilitar a importação de livros estrangeiros" (BRASIL, 1937). No meio tempo dessas transformações, é promulgada, em 1934, uma nova Constituição. 
Ao longo do período imperial, a coroa não permitia a publicação de livros no país, sequer a importação era acessível fora da esfera aristocrática. Com o advento da república, essa realidade começa a se alterar.

A política educacional implantada com a ascensão de Vargas não se restringiu apenas ao controle, fiscalização e normatização dos níveis de ensino. O material didático, utilizado em sala de aula pelos professores, também fez parte desse processo e sofreu modificações referentes a essa política. E os livros didáticos, por serem objetos marcados pelas concepções ideológicas e políticas do autor, foram controlados por legislação específica de fiscalização (WENDT, 2015).

Em 1934, com a promulgação de uma nova Constituição, a valorização sistemática da educação básica, segundo Schwarcz (1999), ainda se mantém. Mesmo no período de D. Pedro II, que desenvolveu alguns aparelhos culturais, o país não havia experimentado uma política de valorização da educação para o grande público. "Com efeito, apesar de obrigatória, a instrução primária era insuficiente: as escolas, poucas, estavam quase todas centralizadas na corte." (SCHWARCZ, 1999, p. 151).

Em 1938, é promulgado o Decreto-Lei $\mathrm{n}^{\mathrm{o}} 1.006$, que dispunha acerca das condições para a produção, importação e utilização do livro didático, subsidiando, ainda, a criação da Comissão Nacional do Livro Didático (CNLD), que tinha como subordinadas as Comissões Estaduais de Livros Didáticos (CELD). Essas comissões tinham como principal atribuição examinar e avaliar o uso dos materiais pedagógicos que circulariam no país, bem como previam a exclusividade editorial do INL para publicar os livros didáticos oficiais que seriam usados nos estabelecimentos de ensino do país. Importante destacar que, 
[...] no que se refere à educação primária, embora a Constituição de 1824 a definisse como obrigação do Estado, pouco foi feito na maioria das províncias nesse sentido. $\mathrm{O}$ governo central cuidava de fato era da educação superior, com exceção da corte e, como vimos, de algumas instituições de ensino secundário que entravam no elenco de predileções do imperador: além do Colégio Pedro II, o Imperial Observatório, o Museu Nacional, o Arquivo Público, a Biblioteca Nacional, o Laboratório do Estado, o Jardim Botânico e a Academia Imperial de Belas Artes. De resto, a falta de instrução era uma grande realidade para a maior parte do país, onde não parecia haver interesses provinciais no aumento do número de cidadãos esclarecidos. (SCHWARCZ, 1999, p. 155).

Moura e Betta (2016) apontam que, no citado DecretoLei $\mathrm{n}^{\mathrm{o}} 1.006 / 1938$, consta a primeira definição jurídica de livro didático no Brasil, marcada por um cunho controlador em termos de produção, o que foi acentuado pelo Decreto-Lei $n^{\circ} 8.460$, de 26 de dezembro de 1945. O Instituto Histórico e Geográfico Brasileiro (IGHB) foi fundado em 1838, menina dos olhos do imperador, a fim de se registrar o que seria considerada a verdadeira história do Brasil. Desenha-se, por intermédio desse órgão,

[...] a construção da ideia de nação no Brasil [que] não se assentou na oposição à antiga metrópole portuguesa; pelo contrário, a nova nação brasileira se reconheceu como continuação da tarefa civilizadora iniciada pela colonização portuguesa. Nação, Estado e Coroa foram elementos pensados como unidade no interior do discurso historiográfico relativo ao problema nacional. (DIEHL, 1998, p. 25).

No ano de 1966, já no regime da ditadura militar, foi criada a Comissão do Livro Técnico e Livro Didático (Colted), por meio de um acordo entre o MEC e United States Agency for 
International Development (Usaid), externalizado pelo Decreto $\mathrm{n}^{\circ} 59.355$ (FILGUEIRAS, 2013), que determinou a participação do Estado no mercado editorial de livros didáticos no que tange à produção, edição, aprimoramento e distribuição (MOURA; BETTA, 2016).

Ainda nos anos 1960, propriamente em 1967, foi criada a Fundação Nacional do Material Escolar (Fename), por meio da Lei $n^{0} 5327 / 67$, como suporte da ampliação da rede escolar, proporcionada pela implantação parcial da Lei de Diretrizes e Bases da Educação Nacional (LDB) de 1961; já no ano de 1971, o INL criou o Programa do Livro Didático para o Ensino Fundamental (Plifed), que absorveu os recursos e trabalhos antes organizados pela Colted, em seguida, no ano de 1976, se extingue o INL, tornando-se a Fundação Nacional de Material Escolar (Fename), responsável pelo Programa do Livro Didático (PLD) (ZACHEU; CASTRO, 2015). Em 1983, a Fename foi incorporada pela Fundação de Assistência ao Estudante (FAE).

Adiante, já sob a égide da redemocratização, é criado o Programa Nacional do Livro Didático (PNLD), pelo Decreto n 91.542, de 19/8/1985. O PNLD está em simetria com o que preceitua a Constituição da República Federativa do Brasil de 1988 (CF/88), quando esta institui, como dever do Estado, a educação (art. 208), especificando o seguinte: "VII - atendimento ao educando, em todas as etapas da educação básica, por meio de programas suplementares de material didático-escolar, transporte, alimentação e assistência à saúde.” (BRASIL, 1988). Sobre o tema, Zambon e Terrazzan expõem o seguinte:

[...] compreendemos o PNLD como programa de distribuição gratuita de obras didáticas de forma sistemática e regular a todos os alunos (individualmente) das escolas de educação básica das redes escolares públicas do País e o consideramos como política 
de Estado, dado seu período de existência e sua permanência desde o ano de 1985, mantendo algumas das características iniciais do programa. (ZAMBON; TERRAZZAN, 2013, p. 587).

Nessa perspectiva, o PNLD avalia e disponibiliza a todo sistema de escolas públicas de educação básica do país obras didáticas, pedagógicas e literárias, entre outros materiais de apoio à prática educativa, de forma sistemática, regular e gratuita. Desde sua criação, essa política foi ampliada, incorporando outros programas e aprofundando seu campo de atendimento. $\mathrm{Na}$ mesma medida em que ocorre essa ampliação, o PNLD também acaba sendo responsável por expressiva parcela do faturamento da indústria livresca no Brasil, tornando-se, sem dúvida, um grande negócio para as editoras (SILVA, 2012).

A última alteração da PNLD ocorreu por meio do Decreto $n^{\circ}$ 9.099, de 18/7/2017, que unifica o Programa Nacional do Livro Didático (PNLD) e o Programa Nacional Biblioteca da Escola (PNBE), originando o Programa Nacional do Livro e do Material Didático (PNLD), que possui uma nova nomenclatura, mas mantém a mesma abreviação.

Em face do exposto, o livro didático se consolida no Brasil como "organizado por editoras, [o] que estrutura o trabalho do professor, em termos de sequenciação dos conteúdos, de atividades didáticas e de sua distribuição segundo o tempo escolar e a seriação". (HORIKAWA; JARDILIN, 2010, p. 154).

\section{0 dispositivo literatura no livro didático: abordagem de Pimentel (2018)}

Esta seção estabelece as premissas emprestadas da contribuição da tese de Pimentel (2018). A priori, destaca- 
se que a pesquisa de Pimentel (2018) apresenta o histórico do material didático distribuído ao longo de todo o século $\mathrm{XX}$, acompanhando as transformações da política educacional no que diz respeito às publicações. No primeiro capítulo, desenvolve o conceito de "dispositivo". A partir disso, busca as relações entre a produção ideológica de conteúdo em contraste com as pretensas definições do que seja a verdade. "Ela [a ideologia] está sempre em oposição virtual a alguma coisa que seria a verdade." (FOUCAULT, 1998, p. 7).

Pimentel (2018) continua pontuando informações interessantes acerca do PNLD, iniciativa governamental que movimenta o mercado editorial brasileiro. A gestão do programa (PNLD) inclui os estados na condução do processo, o que não significa, necessariamente, controle sobre o orçamento do programa.

Cabe, contudo, às unidades federativas e às instituições de ensino a elaboração de um currículo, pois entendese que, partindo desta proposta nacional comum, os estados, municípios ou escolas podem - e devem - propor seu próprio currículo, o que permite que peculiaridades locais e a diversidade que compõe o país sejam contempladas. (PIMENTEL, 2018, p. 20).

No sistema de seleção que representa o PNLD, Pimentel (2018) observa a construção do material de Língua Portuguesa e estuda a intercambiação das referências para a produção (e controle) dos sentidos. Indica que o domínio do campo metafórico é de vital importância para observar as estratégias de poder. "Do navio, elemento sempre móvel, o navegador deve saber em cada ponto, e a cada instante, o lugar onde se encontra." (FOUCAULT, 1998, p. 117). 
O que dá sustentação à tese de Pimentel surge a fim de auxiliar o empreendimento e guia do leitor pelo trabalho: "O conceito dispositivo é uma ferramenta analítica utilizada por Michel Foucault no primeiro volume da História da Sexualidade. É em uma entrevista, contudo, presente na obra Microfísica do Poder (2001), que o conceito de dispositivo é explicitado e definido." (PIMENTEL, 2018, p. 32).

Há necessidade de didatismo para enfeixar o pensamento de Foucault (1998) ao que alimenta a discussão de Pimentel (2018). E para isso, ele traz o necessário para a costura:

Foucault (1998) trabalha com um léxico importado da geografia, que assume o caráter de confronto, como também o estrategismo constante da produção e veiculação dos conceitos. Para ele, a relação ao "silêncio do adversário - (...) é um princípio metodológico —, um princípio tático que se deve sempre ter em mente talvez seja também o sinal de que nós de modo algum lhe metemos medo". (FOUCAULT, 1998, p. 173).

A consciência de que tem em mãos um material a serviço da manutenção do status quo não faz do professor mero condutor de conteúdo alienante, pois cabe a interação em sala com o material que tem em mãos na condução dos embates históricos, sociológicos, antropológicos, filosóficos, científicos a partir de sua cadeira.

Para isso se faz necessária uma regência crítica a partir de seu ponto de vista. É quando entra o dispositivo como gatilho de um desarme institucional, não a favor do mercado, mas da formação cidadã. "Para Foucault, dois diferentes momentos compõem a gênese do dispositivo: a prevalência de um objetivo estratégico e sua constituição como dispositivo." (PIMENTEL, 2018, p. 34). Importante salientar que, ainda com Foucault 
(1998): “O problema não é mudar a 'consciência' das pessoas, ou o que elas têm na cabeça, mas o regime político, econômico, institucional de produção da verdade". (FOUCAULT, 1998, p. 14).

Há relações de poder entre pais e filhos, entre patrões e empregados, entre professores e alunos. Mas também entre diretor e coordenadores de escola, entre estes e professores, o que não significa necessariamente opressão, mas emprego de força que pode se dar de inúmeras maneiras. Para Deleuze, "o poder pode ser matéria de força quando é afetado. Quando pode afetar, é função de força". (DELEUZE, 2005 apud PIMENTEL, 2018, p. 35-36). Entre matéria e função se estabelecem discussões interessantes, tanto na língua portuguesa quanto na física, na química e na matemática, por exemplo.

Desenvolver o vocabulário e as relações entre os conteúdos da grade curricular é tarefa de todos os profissionais da educação que trabalham em sala, no chão de fábrica, como se costuma dizer a partir dos pensadores democráticos da área educacional.

A crise atual destas disciplinas não coloca em questão simplesmente seus limites e incertezas no campo do conhecimento. Coloca em questão o conhecimento, a forma de conhecimento, a norma "sujeito-objeto". Interroga as relações entre as estruturas econômicas e políticas de nossa sociedade e o conhecimento, não em seus conteúdos falsos ou verdadeiros, mas em suas funções de poder-saber. (FOUCAULT, 1998, p. 118).

Ao incorporar a visão foucaultiana, Pimentel (2018) faz algo de extrema utilidade para pensar a componente ideológica que se reveste de discursos em todas as áreas do conhecimento. Espacializando o conceito de panóptico e como é visto por Deleuze, Pimentel aponta que 
Como diagrama, o Panóptico não é a forma que dá objetivo e meios à função de punir, educar ou tratar. Também não é a substância formada (loucos, presos, doentes, estudantes) sobre a qual a função se aplica. Ele atravessa todas as formas e se aplica a todas as substâncias, com a pura função de disciplinar. (PIMENTEL, 2018, p. 36).

A figura do panóptico une as diversas disciplinas na interpretação sígnica, quer seja pelo geometrismo, pelas condições de isolamento, de controle, de edificação. O pensamento de Foucault (1998) cabe perfeitamente em nível médio para contextualizar relações de poder, instrumentalizar o ensino de desenho técnico, subsidiar a engenharia e arquitetura de projetos, os mais variados, não se colocando apenas como conteúdos das ciências humanas e sociais. A percepção de que o poder não existe isoladamente é fundamental para a compreensão do que diz Foucault, uma vez que "o indivíduo não é o outro do poder: é um de seus primeiros efeitos. O indivíduo é um efeito e poder e simultaneamente, ou pelo próprio fato de ser um efeito, é seu centro de transmissão. O poder passa através do indivíduo que ele constituiu". (FOUCAULT, 1998, p. 183-184).

Assimilar que a existência do indivíduo é passível apenas a partir da existência do signo do poder facilita a compreensão da sociedade contemporânea. A Revolução Francesa, a assunção dos direitos e deveres do cidadão, portanto, nada têm de liberdade, mas, sim, de contingenciamento ao conceito de civilização, e, para isso, se faz necessária uma interferência no plano educacional, que vai além do pedagógico, pois

escolas, como instituições, não possuem essência, não possuem anterioridade. Como são práticas e agem como mecanismos operatórios, sua função não é explicar o poder, mas fixar seus dispositivos e aplicar suas tecnologias; é o que Deleuze chama de reproduzir e não produzir. (PIMENTEL, 2018, p. 37). 
O trabalho com a educação é um trabalho de lutas constantes, todas urgentes. Destruir as relações de dominação, socializar a busca pelo conhecimento, respeitar o repertório individual que cada um traz de suas experiências anteriores é tarefa árdua e implica aceitação o tempo todo. Se, caracterizase o dispositivo como grupamento heterogêneo que "engloba discursos, instituições, organizações arquitetônicas, decisões regulamentares, leis, medidas administrativas, enunciados científicos, proposições filosóficas, morais, filantrópicas" (FOUCAULT, 1998 apud PIMENTEL, 2018, p. 32-33), talvez estejamos em direção a uma transformação do modelo.

Existem muitas lutas nesse contexto. Pimentel (2018) nos aponta quais e as relaciona com o pensamento de Michel Foucault (1998): "São as lutas sociais: 1) as formas de dominação (étnica, social, religiosa); 2) as formas de exploração (que separam os indivíduos daquilo que produzem); 3) as formas de subjetivação e submissão (que ligam o indivíduo a si e o submetem)." (PIMENTEL, 2018, p. 40).

Compreender o papel da escola é relacionar o conjunto das lutas no sentido de enfrentar o que nos divide. A escola não pode se furtar a discutir questões ligadas aos itens colocados por Pimentel (2018), sob pena de não cumprir seu papel maior que é o de democratizar o ensino para todos. Não se trata apenas do acesso físico, mas do direito de ir e vir, de se expressar livremente, de ter garantidas suas opções, opiniões, engajamentos. Isso é também uma concepção de partilha do poder, sem diminuir o controle sobre o que é de fato importante na condução dos processos, ou seja, uma concepção em que se veja "o poder como um feixe de relações, mais ou menos organizado, ou ainda, mais ou menos piramidalizado, funcionando com alguma coordenação". 
(PIMENTEL, 2018, p. 48). Mas cabe um alerta: "Existe uma administração do saber, uma política do saber, relações de poder que passam pelo saber." (FOUCAULT, 1998, p. 158).

Assim, a pesquisa de referência (PIMENTEL, 2018) desperta o pensar na produção e reprodução discursiva como base para a difusão do conhecimento. Quando facilita o acesso ao pensamento de Foucault (1998), deixa mais claro que a exclusão do discurso passa por enxergar os interditos da palavra, a segregação de quem foge ao senso comum, como também os que estabelecem o púlpito das verdades absolutas. (PIMENTEL, 2018 , p. 73). Se os procedimentos internos do discurso se constituem pelos comentários, pela questão da autoria e o rigor da disciplina, deve-se pensar na descontinuidade como imanência, o que faz de nós mesmos, muitas vezes, reféns de discursos descabidos, sem o peso de uma verdade absoluta. "Discursos são práticas descontínuas, que podem se cruzar, mas também podem ignorar-se ou até se excluir." (PIMENTEL, 2018, p. 86).

Quando o aluno chega ao resultado esperado pelos autores do livro didático, que visam a prepará-lo para o exame de aptidão e o bom recebimento pelo mercado, isso não significa que teve bons professores, mas que estes cumpriram a expectativa que o governo federal depositou no professorado. A satisfação pelos proventos salariais tem ligação com o sucesso dos alunos na recepção universitária ou no mercado de trabalho.

Por fim, ressalta-se a importância dada por Foucault (1998) aos procedimentos externos da produção do discurso, à interdição da palavra - que exibe discordância de quem exerce o poder sobre ela (o professor), à superação do contraditório (exercida pelas variações do discurso) e à sujeição à verdade (exclusão de um pensar diferente), que são características de 
processos antidemocráticos, como, por exemplo, a realização de um exame para admissão ao ensino superior, o que justifica a pirâmide educacional e o afunilamento de oportunidades.

\section{0 dispositivo literatura no livro didático e a educação brasileira: reflexões do cenário pós-pandemia}

Apesar de existir desde 2004, nos últimos anos, se acentua, no país, a polêmica de se instituir uma escola sem partido, objetivo de um governo que busca se ausentar das políticas públicas de democratização do ensino (KOGAWA; TEIXEIRA, 2020).

Alimentando na população a ideia de que professores são veiculadores de conceitos comunistas, ou retroalimentadores de uma anarquia institucional, ou ainda pregadores de uma seita em que o ceticismo religioso obscurantiza a implementação de um velho testamento contemporâneo, o discurso fascista demarca claramente a utilização de mecanismos de controle social, a fim de obter dividendos políticos eleitorais.

Cada sociedade tem seu regime de verdade, sua "política geral" de verdade: isto é, os tipos de discurso que ela acolhe e faz funcionar como verdadeiros; os mecanismos e as instâncias que permitem distinguir os enunciados verdadeiros dos falsos, a maneira como se sanciona uns e outros; as técnicas e os procedimentos que são valorizados para a obtenção da verdade; o estatuto daqueles que têm o encargo de dizer o que funciona como verdadeiro. (FOUCAULT, 1998, p. 12).

Ocorre que a pandemia do novo coronavírus serviu como ponto de inflexão para esse discurso. Não apenas por questões ligadas à ideologia, mas, sobretudo, pelo fato de que a população 
que mantém filhos nas escolas públicas, ou mesmo privadas, se viu sem saber o que fazer com crianças e adolescentes em casa, sentindo na pele como é o trabalho docente e as condições mínimas que o agente deve ter para realizá-lo a contento.

Educação e saúde são peças importantes em qualquer governo, haja vista o montante do orçamento destinado às políticas públicas. O governo de Getúlio Vargas uniu as duas pastas em uma, sob o comando do todo-poderoso Gustavo Capanema, mineiro utilizado para minimizar a insatisfação das Minas Gerais após o rompimento da política café com leite. Foucault (1998) traz, de sua pesquisa em torno da saúde, elementos cruciais para se pensar o dispositivo. Com relação ao surgimento da medicina social, por exemplo, sabe-se que:

O controle da sociedade sobre os indivíduos não se opera simplesmente pela consciência ou pela ideologia, mas começa no corpo, com o corpo. Foi no biológico, no somático, no corporal que, antes de tudo, investiu a sociedade capitalista. O corpo é uma realidade biopolítica. A medicina é uma estratégia bio-política. (FOUCAULT, 1998, p. 80).

A reflexão acerca da medicina social acaba colocando em destaque o corpo como importante estratégia para o controle da sociedade, pois é um dos meios empregados para chegar a determinado fim; uma maneira pela qual se tem vantagem sobre o outro; parte dos procedimentos utilizados para que a sociedade renuncie à luta.

A partir desses elementos, desloca-se o olhar para a interação educacional. Se o professor de língua portuguesa pede ao aluno para escrever um poema, precisa mostrar a ele que sabe fazê-lo; o mesmo com a crônica, um texto argumentativo, um romance. Via de regra, o docente de língua materna não precisa 
ter essas habilidades todas, mas saber conduzi-las é fundamental.

É preciso compreender os conceitos, antes de colocá-los em funcionamento ou análise. Assim, o conjunto de conhecimentos a ser partilhado é fruto de um conjunto elaborado ao longo da existência humana, revisado periodicamente para se compor esse dispositivo estratégico chamado episteme,

que permite escolher, entre todos os enunciados possíveis, aqueles que poderão ser aceitáveis no interior, não digo de uma teoria científica, mas de um campo de cientificidade, e a respeito de que se poderá dizer: é falso, é verdadeiro. E o dispositivo que permite separar não o verdadeiro do falso, mas o inqualificável cientificamente do qualificável. (FOUCAULT, 1998, p. 247).

Cabe aqui a preocupação atualizada com as fake news, banalizadas ultimamente no cenário de uma pós-verdade anunciada. Mas o que seria essa nova agente que atua nos processos de subjetivação, se não uma "espécie de segunda onda do pós-modernismo. Sua consequência é ao mesmo tempo lógica e reveladora da verdade brutal e esquecida na qual ambos se apoiam". (DUNKER, 2017, p. 13).

A produção acelerada de conteúdo, acentuada pela irrupção, no meio estudantil, de uma pandemia que assola o processo de ensino-aprendizagem, como as demais práticas contemporâneas, ressignifica a ferro e fogo a ensinagem.

O livro didático torna-se uma abstração diante do cenário imposto. E a abstração cabe em qualquer circunstância. "Foucault entende que a conceituação não deve estar fundada em uma teoria do objeto, mas em quais condições históricas a conceituação é motivada e qual o tipo de realidade com a qual se lida." (PIMENTEL, 2018, p. 38). Interpretar o momento, a cidade, 
a escola, o país, o mundo é atividade constante do processo. O conhecimento, para ser válido, deve vir acompanhado da contextualização, sempre.

No que diz respeito ao Exame Nacional do Ensino Médio (Enem), sua guinada para contextualizar os conteúdos foi a oportunidade para os professores que não trabalhavam dessa forma fazê-lo. Talvez estejamos diante de novos dispositivos, gestados em uma transição de plataformas. O pensador francês diz entender o dispositivo "como um tipo de formação que, em um determinado momento histórico, teve como função principal responder a uma urgência”. (FOUCAULT, 1998, p. 244).

Há outro inimigo feroz da educação e que prolifera a olhos vistos com a explosão das mídias sociais: o senso comum. Há poetas, cientistas, ambientalistas e críticos literários nas páginas de todas as redes sociais. O perigo da disseminação desse conhecimento raso de qualquer assunto tem causado preocupação.

O senso comum é um conhecimento evidente que pensa o que existe tal como existe e cuja função é a de reconciliar a todo custo a consciência comum consigo mesma. É, pois, um pensamento conservador e fixista. A ciência, para se constituir, tem de romper com essas evidências e com o código de leitura do real que elas constituem. (SANTOS, 1989, p. 32).

Desde a Revolução Francesa (1789) aos dias de hoje, observamos os processos crescentes de individualização, importantes no combate ao autoritarismo imperial, mas que se perderam ao longo do tempo na confusão conceitual e prática de direitos e privilégios. Não se luta por privilégios, mas por direitos, "o estudo do ser, inserido em feixes de relações de 
saber e poder permite olhar a história com ênfase nas práticas sociais que fizeram - e fazem - de nós aquilo que somos". (PIMENTEL, 2018, p. 51).

Ao trazer fragmentos da LDB que garantem à escola a implementação de conteúdos fundamentais para que se propague a ideia de equidade no conhecimento, Pimentel (2018) contribui para reforçar o dinamismo da cultura em sua mescla, esse amálgama que nos faz iguais a todos. $\mathrm{O} \S 2^{\circ}$ dá conta dessa atitude certeira, que agora está em risco pela ascensão fascista que ronda as antessalas do poder: " $\$ 2^{\circ}$ Os conteúdos referentes à história e cultura afro-brasileira e dos povos indígenas brasileiros serão ministrados no âmbito de todo o currículo escolar, em especial nas áreas de educação artística e de literatura e história brasileiras." (BRASIL, 1996).

Pensa-se o papel da escola como auxiliar na promoção dos discursos. A CF/88 deve continuar garantindo o direito à livre expressão, mas esta não pode ou deve ser confundida com a veiculação de ideias que contrariem os direitos humanos, que desrespeitem a igualdade dos indivíduos que compõem a nação. Por outro lado, não se aceita mais como verdade uma intromissão de qualquer ordem na livre expressão do cidadão. Pondera-se que nem

a dialética (como lógica de contradição), nem a semiótica (como estrutura da comunicação) não poderiam dar conta do que é a inteligibilidade intrínseca dos confrontos. A "dialética" é uma maneira de evitar a realidade aleatória e aberta desta inteligibilidade, reduzindo-a ao esqueleto hegeliano; e a "semiologia" é uma maneira de evitar seu caráter violento, sangrento e mortal, reduzindo-a à forma apaziguada e platônica da linguagem e do diálogo. (FOUCAULT, 1998, p. 5). 
Para buscar disciplinar os excessos, existe um aparato jurídico que contém um conjunto de doutrinas que atuam para reprimi-los. Se a noção de discurso precisa ser mais bem trabalhada, a escola o deve fazer, já que, em nosso meio, "a educação é o instrumento que permite aos indivíduos o acesso a discursos diversos - a regularidade e a dispersão são marcas de sua prática”. (PIMENTEL, 2018, p. 72).

Nesse cenário, o dispositivo literatura no livro didático deve ser estruturado por leituras contextualizadas, a fim de se promover a autonomia dos estudantes. Como exemplo, no livro didático Português: contexto, interlocução e sentido, de Abaurre, Abaurre e Pontara (2016), o pré-modernismo (período de transição que vai de 1902 a 1922) é tratado como período de intensa contestação, em que a incipiente velha república tentava se afirmar em oposição à tradição monárquica que perpetuou uma série de costumes do patriarcado vigente até hoje.

Outro exemplo seria como o citado livro possibilita ao docente uma abordagem diferenciada da figura emblemática de Euclides da Cunha, oficial da Academia Militar das Agulhas Negras (Aman) que ousou contestar o fenômeno de Canudos em seu épico literário-sociológico Os Sertões. O livro didático parte dessa premissa para questionar os caminhos republicanos ao longo do século XX, a partir da emersão do tema: o sertão vai virar mar ou o mar vai virar sertão. Então, o dispositivo literatura no livro didático pode ser visto como ponto de partida para discutir simultaneamente questões sociológicas, filosóficas, políticas, econômicas, humanísticas e outras.

O amálgama resultante da pandemia, pós-verdade e fake news acaba apontando desafios e reflexões futuras para a literatura e o livro didático no espaço da escola brasileira. As dificuldades 
do ensino remoto evidenciaram a fratura exposta do pensamento neopositivista que recobre a formação docente. A revisão de posturas e adequação às plataformas digitais ocorreu de modo abrupto e sem qualquer planejamento. Dentre os desafios que se avizinham para o pós-pandemia pode se apontar a necessidade premente de uma formação continuada no que diz respeito às novas tecnologias e a compartimentação do conhecimento em novos repositórios de conteúdos.

O uso de plataformas, programas e de extensões de variado calibre reúne uma série de procedimentos que facilitam a interface com o usuário, embora encontre limitações de acesso à rede mundial de computadores, por um lado, como a resistência cultural de parte da comunidade docente, por outro. Com o potencial que as redes sociais hoje têm, o manancial de informações disponibilizadas em bancos de dados de várias naturezas e o crescente comércio de produtos eletrônicos com dispositivos que permitem o acesso à rede mundial de computadores, o que é preciso é implementar políticas constantes de formação docente.

O ensino de literatura pode contribuir de modo a sistematizar a aplicação de seus conteúdos para além da periodização dos estilos e centrando o foco no estudo dos elementos textuais que caracterizam o texto literário, a saber: definições e uso da literatura como ferramenta pedagógica, a exploração dos sentidos e a dinamização dos olhares para o texto como objeto significativo. Complementando, parece que a formação continuada de professores no sentido de buscar os conhecimentos disponibilizados nesse amplo espectro de nuvens e outros repositórios é fundamental. Conhecer as ferramentas que interagem com o livro didático é o ponto nevrálgico 
para esse período pandêmico e pós-pandêmico. Literatura digital, produção de e-books e construção de aplicativos que democratizem a leitura para além do papel é outro ponto que merece destaque.

Se, por um lado, o dispositivo implica ordenamento, por outro, pode contribuir para um autoletramento que, em médio e longo prazo, pode garantir certa autonomia intelectual. Por seu turno, a literatura possui a propriedade de contornar (“driblar") a realidade ao mesmo tempo que a transforma. Dessa forma, o dispositivo literatura no livro didático tem o potencial, em um mundo pós-pandemia, de continuar a ser um instrumental que recompõe e dá sentido à carpintaria do ser estudante, do ser escritor, do ser leitor e do ser crítico.

\section{Considerações finais}

Tendo o livro didático como referência, as políticas públicas insuficientes para se valorizar os livros e a educação, os pontos de inflexão, como a pandemia do novo coronavírus, exemplificase um pouco da complexidade da estrutura colonial imposta aos nativos e demais habitantes deste país.

$\mathrm{O}$ ensino de literatura brasileira pode ser efetuado a partir de elementos-chave. Aborde-se, por exemplo, a questão nativista. Os cronistas (que eram portugueses) leram o território e se estabeleceu a literatura dos viajantes. Os românticos (nacionalistas) leram os cronistas e produziram seu recorte nacionalista (idealizado). Os modernistas leram os cronistas (poesia pau-brasil) e os românticos. Chico Buarque (1998) envolve a todos de maneira sintética com "Iracema voou", poema (musicado) transcrito abaixo. Essa obra dialoga com 
a construção do conceito de brasilidade e suas nuances todas, oferecendo, por exemplo, material para se refletir sobre o período colonial e o desenvolvimento da cultura miscigenada e de caráter exploratório a que se submeteu (ou foi submetido) nosso país. Iracema voa, enquanto Martim, personagem de José de Alencar, vem de caravela para cá. Ela vai de avião, portanto, só pode ter acontecido após a invenção do veículo, no início do século XX.

\author{
Iracema voou \\ Para a América \\ Leva roupa de lã \\ E anda lépida \\ Vê um filme de quando em vez \\ Não domina o idioma inglês \\ Lava chão numa casa de chá \\ Tem saído ao luar \\ Com um mímico \\ Ambiciona estudar \\ Canto lírico \\ Não dá mole pra polícia \\ Se puder, vai ficando por lá \\ Tem saudade do Ceará \\ Mas não muita \\ Uns dias, afoita \\ Me liga a cobrar \\ É Iracema da América
}

(BUARQUE DE HOLANDA, 1998).

Os desafios no horizonte são enormes e quanto antes começarem a ser mensurados, maiores as chances de se obter sucesso com antecedência. O futuro já chegou; o complexo de vira-lata a que Nelson Rodrigues se referiu há algum tempo precisa ser definitivamente afastado de nossa cultura, sob a pena de permanecermos eternamente sentados em berço esplêndido, a exemplo de qualquer cão abandonado nas ruas, a correr atrás do próprio rabo. 
Portanto, vê-se a necessidade de o processo de ensinoaprendizagem continuar a trabalhar comleituras contextualizadas, principalmente no cenário pós-pandemia, a fim de se promover a autonomia dos estudantes. A crise sanitária acaba por acelerar mudanças no uso das tecnologias em um panorama marcado por externalidades como a pós-verdade, o senso comum e as fake news. Logo, o dispositivo literatura no livro didático precisa se aproximar e migrar para as mídias, visando à democratização da leitura para além do papel. Essa nova realidade pressiona a formação continuada de educadores no sentido de buscar os conhecimentos disponibilizados nesse amplo espectro de nuvens e outros repositórios.

Encerra-se este artigo com a expectativa de que o desenvolvimento da prática de leitura se ofereça a todos, em igualdade de condições, para que, de fato, consolide-se uma política de suprimento informacional a fim de que se possa melhorar a aptidão da leitura e interpretação de textos.

\section{Referências}

ABAURRE, Maria Luzia M.; ABAURRE, Maria Bernadete M.; PONTARA, Marcela. Português: contexto, interlocução e sentido. 3. ed. São Paulo: Moderna. 2016.

BRASIL. Constituição da República Federativa do Brasil: promulgada em 5 de outubro de 1988. Brasília, 1988.

BRASIL. Ministério da Educação. Decreto-Lei no 93, de 21 de dezembro de 1937. Cria o Instituto Nacional do Livro. 1937.

BRASIL. Ministério da Educação. Lei no 9.394, de 20 de dezembro de 1996. Estabelece as diretrizes e bases da educação nacional. 1996. 
BUARQUE DE HOLANDA, Chico. Iracema voou. In: BUARQUE DE HOLANDA, Chico. Chico ao vivo. Rio de Janeiro: Universal. 1998. CD duplo.

CHOPPIN, Alain. História dos livros e das edições didáticas: sobre o estado da arte. Educação e Pesquisa, [s. l.], v. 30, n. 3, p. 549-566, 2004.

DIEHL, Astor Antônio. A cultura historiográfica brasileira: do IGHB aos anos 1930. Passo Fundo: Ediupf, 1998.

DUNKER, Christian. Subjetividade em tempos de pós-verdade. In: DUNKER, Christian et al. Ética e pós-verdade. Porto Alegre: Dublinense, 2017. p. 09-41.

FILGUEIRAS, Juliana Miranda. As avaliações dos livros didáticos na Comissão Nacional do Livro Didático: a conformação dos saberes escolares nos anos de 1940. Revista Brasileira de História da Educação, [s. l.], v. 13, n. 1 [31], p. 159-192, jan.-abr. 2013.

FOUCAULT, Michel. Microfísica do poder. 13. ed. Rio de Janeiro: Graal, 1998.

HORIKAWA, Alice Yoko; JARDILIN, José Lima. A formação de professores e o livro didático: avaliação e controle dos saberes escolares. Rev. Lusófona de Educação, Lisboa, n. 15, p. 147$162,2010$.

KOGAWA, João; TEIXEIRA, Maria Aline Plácido. A polêmica de uma escola sem partido: pelo sim/pelo não à doutrinação. Revista Olhares, Guarulhos, v. 8, n. 1, abr. 2020.

MOURA, Sérgio Arruda de; BETTA, Thiago Eugênio Loredo. O livro didático enquanto política pública e gênero discursivo em circulação no Brasil. Revista Científica Internacional, [ $s$. l.], v. 11, n. 2, art. 7, abr.-jun. 2016.

PIMENTEL, Paulo Sesar. O dispositivo literatura no livro didático. 2018. 148 f. Tese (Doutorado em Psicologia) - UFF, Niterói, 2018. 
SANTOS, Boaventura da Silva. Introdução a uma ciência pósmoderna. Rio de Janeiro: Graal, 1989.

SAVIANI, Dermeval. Histórias das ideias pedagógicas no Brasil. Campinas: Autores Associados, 2019.

SCHWARCZ, Lilia Moritz. As barbas do imperador: D. Pedro II, um monarca nos trópicos. São Paulo: Companhia das Letras, 1999.

SILVA, Marco Antônio. A fetichização do livro didático no Brasil. Educ. Real., Porto Alegre, v. 37, n. 3, p. 803-821, set.dez. 2012.

WENDT, Wanessa Tag. A república nos livros didáticos de História da Era Vargas (1938 - 1945). 2015. 149 f. Dissertação (Mestrado em História) - Pontifícia Universidade Católica do Rio Grande do Sul, Porto Alegre, 2015.

ZACHEU, Aline Aparecida Pereira; CASTRO, Laura Laís de Oliveira. Dos tempos imperiais ao PNLD: a problemática do livro didático no Brasil. In: JORNADA DO NÚCLEO DE ENSINO DE MARÍLIA, 14., Marília - SP, UNESP, 2015. p. $1-12$.

ZAMBON, Luciana Bagolin; TERRAZZAN, Eduardo Adolfo. Políticas de material didático no Brasil: organização dos processos de escolha de livros didáticos em escolas públicas de educação básica. Rev. Bras. Estud. Pedagog., Brasília, v. 94, n. 237, p. 585-602, ago. 2013. 